
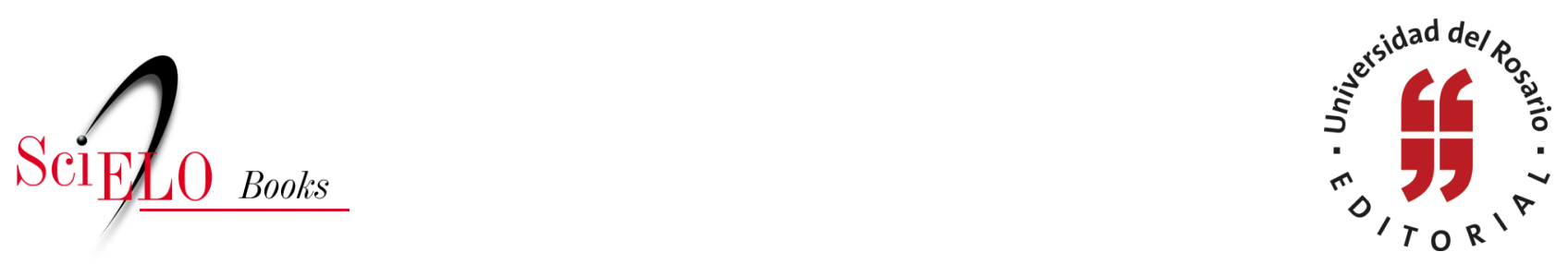

\title{
12. La huelga del 69 (segunda parte)
}

\author{
César Augusto Tapias Hernández
}

\section{SciELO Books / SciELO Livros / SciELO Libros}

TAPIAS HERNÁNDEZ, C.A. La huelga del 69 (segunda parte). In: Historias de familia: Etnografía delirante sobre el amor, la violencia y las drogas [online]. Bogotá: Editorial Universidad del Rosario, 2014, pp. 49-54. Textos de ciencias humanas collection. ISBN: 978-958-738-543-4. https://doi.org/10.7476/9789587385434.0013.

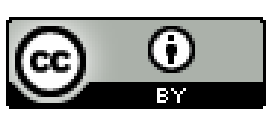

All the contents of this work, except where otherwise noted, is licensed under a Creative Commons Attribution 4.0 International license.

Todo o conteúdo deste trabalho, exceto quando houver ressalva, é publicado sob a licença Creative Commons Atribição 4.0.

Todo el contenido de esta obra, excepto donde se indique lo contrario, está bajo licencia de la licencia Creative Commons Reconocimento 4.0 . 


\title{
12. La huelga del 69 (segunda parte)
}

\author{
La cohesión del grupo era contra los jefes; ahora hay una \\ adhesión de obreros contra obreros. \\ Pierre Bourdieu, "Hamid", en La miseria del mundo
}

El tío Jaime apenas pudo regresar a casa desde la "cana”, como a las cuatro o cinco de la tarde: "Todo cagao, mal oliente".

Al otro día, se suponía que les esperaba de nuevo el trabajo, a él y sus compañeros... ¡ Vaya sorpresa la que se llevaron! A los dirigentes del sindicato, principalmente, el portero no les permitió la entrada: mientras a la empresa ingresaban todos los demás, Jaime y sus "compas" esperaban afuera.

- Entraron todos y con las que nos salió el portero era que firmáramos la tarjeta y que volviéramos a las dos a firmar otra vez la tarjeta. Así nos la pasamos varios meses, recibiendo el sueldo sin trabajar, jugando billar por ahí cerca pa’ alcanzar a ir a firmar...

Pero no crean que lo del presidente de la República queda agotado con la llamada telefónica que él mismo hizo a Peldar el día de la huelga. Quedó claro que las intenciones eran despedir cerca de 400 empleados, cosa que no autorizó el gobierno nacional, que solo quería la cabeza de los dirigentes sindicales de cada una de las sedes de Peldar, pues la huelga de 1969 bien podría llamarse la huelga mundial, como a ella se refiere Teresa, la esposa del tío, pues las plantas de Barranquilla, Zipaquirá y Envigado protestaron al mismo tiempo. El problema ( $y$ la pelotera) fue en el ámbito nacional, y la solución también debía serlo entonces. Así las cosas, continúa Jaime "Pereque" con el relato de una historia que hizo escala en la Casa de Nariño:

- Le pedimos una audiencia al m... ese, y nos la dio. Nos estuvimos en Bogotá como ocho días. Uno va a una oficina en el Palacio de Gobierno, y en una oficina se tramita la solicitud que el presidente acepta solo en casos especiales. Nos acep- 
taron, pero no a todos. Entramos solo tres, cada uno representando a una planta: por Barranquilla, un moreno grande llamado Douglas; de Zipaquirá, no recuerdo el nombre del tipo, y yo, por la de Envigado...

-Y ¿cómo era Lleras?

_Un cabecipelado él, bajito, malacaroso.... malaclase.

-Les acepté la audiencia solo porque quería conocerlos y pa’ que me vieran. Digan lo que digan, aquí no hay arreglo, ustedes van para afuera — dijo el presidente.

- Pero, doctor - intervino Jaime - usted no puede hacer eso, ¡echarnos!, se formará de nuevo el tropel ese, los trabajadores están dispuestos a todo.

-Yo asumo las consecuencias — dijo el señor presidente- y fin de la reunión.

Cuenta el tío que la reunión con don Lleras fue a las 11:00 de la mañana y a las 4:00 de la tarde ya estaba en Medellín. La siguiente parada era la empresa para pasar un informe a los compañeros y ver qué se hacía. Si bien no se aprobó el despido masivo, el de los líderes era un hecho. A través del portero de la empresa mandaron llamar a sus representantes adentro. Como no podían entrar, otros dirigían la cosa. La idea sí era atacar de nuevo; pero los de adentro rindieron informe: "por lo menos unos cien soldados están aquí como desde la 1:00 de la tarde...”.

Esta historia está siendo recreada treinta y punta de años después en el patio de una casa donde se habita y se trabaja. Y Teresa, la mujer de Jaime, haciendo lo suyo en la cocina, pero toda conectada a la evocación, trasladada a esos tiempos, contribuye incluso en la composición del relato:

-Mientras estos venían, el viejo ese se les adelantó y les llenó la planta de policías y ejército...

—No había remedio - retoma don "Pereque"-. Y para ajustar, el portero nos entregó la carta de despido firmada por el propio presidente de la República; pero eso no es todo; no había opción alguna de recomendación para otra empresa. Ahí sí... ¡se cagaron en nosotros!

Sin embargo, aquello fue noticia nacional y unos compañeros suyos comenzaron a ir los días de pago a otras grandes empresas como Tejicondor, Fabricato, la FLA, Coltejer, etc., pidiendo colaboración para los compañeros despedidos de Peldar, y se recogían un platal el hifuemadre que entre los despedidos se repartía...; pero eso no fue cosa de mucho rato, la gente se cansó de dar plata.

- Jaime empezaba a decir que vivíamos era de limosna — sonriente cuenta Teresa-. Con el tiempo nos tocó arreglárnoslas solos...

Terminó por aquellos días administrando el tío un negocio que papito Gabriel montó en la América, recién llegado de Estados Unidos. 
- Popalito, un amigo mío, me dijo un día que yo estaba en una foto allá en la gobernación tachado de sindicalista revolucionario. Mejor dicho, si eso hubiera sido hoy, iya nos hubieran matado!

Finalmente, como dice mi tía Irene y la prima Omaira, el tío Jaime se dio el gusto de ser echado por el mismísimo presidente de la República. Una situación que hoy en día él contempla con sonrisa; pero sin evitar que sus ojos se chocolateen. Debe de habitarle la tristeza y la frustración a mi tío Jaime, alias "Pereque", como le dice su esposa. Y es que atrás, más allá de más de diez años consagrados a una empresa, quedaron amigos y una situación que, sin duda, debió de enseñarle bastante.

Y más que haber conocido al presidente, a mí personalmente me asombró ese dato del tío, su capacidad de mirar todo, con obvia nostalgia, pero sin dejar de reconocer errores, algo que no es solamente de ahora 30 años después... De regreso a la planta, el mismo día de la audiencia con el presidente Lleras, los dirigentes pensaron en sus compañeros, y siendo honestos prefirieron dejar las cosas así como iban, ¿para qué pelear más?...

El tío no pudo ubicarse de nuevo en una fábrica; pero no por eso se quedó ahí. Digamos que el tío es hoy una especie de microempresario donde el único jefe es él y sus trabajadores son aquellos (familia o gente cercana a veces) que rentaron sus locales de ventas de comidas rápidas, y evitándose así, de paso, que le monten un sindicato. Y hasta de pronto, que le hagan paro.

$\infty \infty \infty$

Las etnografías dependen de la naturaleza de la audiencia. Esto aplica en casi todo el libro si pensamos que la audiencia primera es mi familia, y ante ellos mantengo el compromiso de posibilitar una comprensión diferente de las cosas, como para ir más allá de comparaciones con manifestaciones de sorpresa. Todo cuanto hay aquí no nos sorprende. Este viaje, esta etnografía, este cuento largo... solo ha descrito mi traslado desde la pregunta inicial hasta el intento de su comprensión, de forma similar a cómo Marlow remonta el río Congo en busca de Kurtz (Conrad, 1899 [1996]).

Sin embargo, esta etnografía también está pensada para los colegas y demás investigadores... Es un documento para contribuir a historiografiar no solo la cultura, sino la forma de abordar el objeto... Desde ahí debo decirles que, como Marlow, fui testigo de experiencias extremas, yendo al corazón de las tinieblas. Esta etnografía debe verse como el registro de un proceso emergente, remontando un 
caudaloso río lleno de dudas, de preguntas, de experiencias que, una vez escritas, intentan transferir esas dudas al lector... Es más que una reseña familiar específica: propone aspectos de los miembros de un complejo grupo social en un momento determinado, un grupo humano que ha estado viviendo en el mundo antes de que yo apareciera con mis preguntas, y que continuará viviendo después de cerrar este libro.

En síntesis, es una etnografía en función del grupo estudiado (Agar, 2008), de sus valores: datos perfectos, objetivamente obtenidos, reescritos a manera de memorias, de poemas... y... la interpretación antropológica que resulta es ficcional, sí, una ficción en el sentido de que es algo "hecho", algo "formado", algo "compuesto" a partir de recuerdos facilitados oralmente, en intercambios más o menos simétricos, discursos autobiográficos que, como dice Gramsci (1975), documentan molecularmente la explosión social, o en palabras de Bourdieu (1989), ilusiones biográficas no necesariamente falsas por ser imaginadas, mucho menos inefectivas. Son un experimento de escritura, que me permite afirmar con Geertz (1973) que lo que primordialmente hace un antropólogo es escribir. Y eso he hecho: desvelando las formas invisibles de cómo funciona la estructura social que conformamos. Recordar que soy miembro del grupo observado, un narrador no protagonista pero involucrado... intentado crear una evocación... y lo que ha terminado por construir, son fragmentos de sus vidas, sus cambios históricos, que una vez relatados, parecen cuentos inventados pero que en realidad son el resultado de escribir sobre su cultura.

$\infty \infty \infty$

Observar la cotidianidad de los personajes durante este viaje constituyó una posibilidad metodológica; pero la resolución de las preguntas solo fue posible de forma dialéctica, contradictoria: mostrando qué es una cosa y qué no lo es (¿quién soy y quién no puedo ser?). A partir de las interacciones con mis familiares y la escritura de las viñetas o historias de este inventario, recurrí a los aportes de varias teorías.

Para comenzar, Norbert Elías (1983), quizás el filósofo social más completo, para quien el objeto de estudio de la sociología es la interdependencia de los individuos: la sociedad como un tejido cambiante y móvil de interdependencias múltiples que vinculan recíprocamente a los sujetos. Mi hermano, sus aprendizajes, el taller de mi papá, mi papá... su violencia, mi mamá, yo... mis tíos, el barrio, el guaro, las drogas: tejido social, configuración social, sistema social, formas específicas de interdependencia entre nosotros mismos, red de intercambios, de intersubjetividades entrelazadas y la mayoría de las veces desequilibradas, porque aquí también existe la 
desigualdad, la dominación y el poder desquiciado junto a formas morales y éticas por construir. Y ni qué decir de la violencia como un recurso para esa construcción de lo social. Incluso la violencia emocional. Ya se trate de héroes, bandidos, sabios, mujeres solteras o con hijos, abandonadas u olvidadas... me parece que es la violencia la que consolida la unión del habitus como historia hecha cuerpo, y del campo como historia hecha cosa, el mecanismo principal de la producción del mundo social (Bourdieu, 2000): conjunción, movimiento, interiorización del exterior y de exteriorización de lo interior. Es lo que llamamos en sociología salidas dialécticas sobre repertorios ampliamente difundidos entre diversos sectores de una sociedad, saberes intergeneracionales que se mantienen como ecos que naturalizan lo aprendido. ¿Qué es ser hombre? ¿Qué es ser mujer? ¿Cómo serlo y cómo dejar de serlo?

$\infty \infty \infty$

Hasta 1860, ni siquiera se podía pensar en una historia de la familia. Las ciencias históricas hallábanse aún, en este dominio, bajo la influencia de los libros de Moisés. (Engels, 1884) ¿Por qué no escribir la historia de una familia? Más aún... ¿las historias de mi familia? Era allí donde podía contrastar la realidad con mis inquietudes frente a elementos que constituyen el mundo social contemporáneo. $\mathrm{O}$ ¿cómo explicar la articulación de las formas sociales pasadas con las formas sociales nuevas? ¿Cuáles son unas y otras? ¿Cómo se conjugan las herencias y la obra social cotidiana? Esta etnografía se convierte en la posibilidad de ver el fenómeno de la familia cerrarse un poco a poco sobre sí mismo. Mi familia confrontada sobre sus repeticiones, sobre sus configuraciones. Porque pensar la familia como una categoría sociológica implica considerarla más que como institución (Corcuff, 2005), como una estructura social en movimiento, plena de interacciones, es decir, una acción social, una experiencia vivida, un acto no necesariamente contemplado reflexivamente; pero en camino de serlo, y como tal, posible de desarmarse, to strip, diría Goffman (1974), pensando en cualquier fenómeno social (adecuadamente) delimitado y contra el cual el etnógrafo (yo mismo) pudiera poner a prueba su comprensión, considerando como centro de análisis, para el caso de este libro: la intersección entre lo colectivo y lo individual.

¿Es posible aislar lo colectivo de lo individual? (¿Mi forma de ser contra la de mi padre?) A este respecto, Émile Durkheim (1895 [1975]) continúa siendo una referencia obligada, ya que su idea de lo colectivo remite a la idea de presiones exteriores impuestas a las personas y a un ámbito de validez que trasciende las conciencias 
individuales. Es la inconclusa obra inédita de Alonso Buitrago, un sociólogo colombiano inédito que se pregunta por hijos sin madre, por padres sin hijos, por amantes sin remordimientos. ¿Cómo ser unos hijos de puta que no necesiten la familia para no venerar la esclavitud? (Buitrago, 2012) Sí, es que somos esclavos formados en la familia. De ahí que las madres se crean dueñas de sus hijos. Es de locos. La familia es de locos. Y mi familia no es la excepción. Está conformada por locos de amor, de entusiasmo, de aguardiente, de rencores, de dolores... Creo que para avanzar nos viene bien modificar aún más los estados de la conciencia, así que la siguiente invitación es a embriagarnos, como lo propone el gran poeta del siglo XIX, Charles Baudelaire: "embriagaos de cualquier cosa”. Incluso de la realidad, acotaría una instructora de yoga. 